\title{
Incidental case of primary renal lymphoma (PRL) in a patient with chronic hepatitis $\mathbf{C}$ infection. Report of a rare case
}

\author{
Mircea LitesCu ${ }^{1,2)}$, Ion Daniel Baboi ${ }^{3)}$, Laura Paverman ${ }^{3)}$, Camelia doina VRabie ${ }^{2,4)}$,

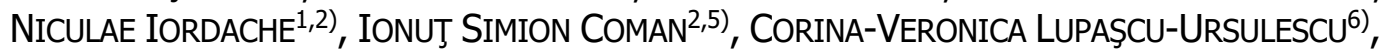 \\ ION DINA ${ }^{2,3)}$, VALENTIN TITUS GRIGOREAN ${ }^{2,5}$ \\ 1) Department of General Surgery, Sf. Ioan Emergency Clinical Hospital, Bucharest, Romania \\ 2) Department of Surgery, Carol Davila University of Medicine and Pharmacy, Bucharest, Romania \\ 3) Department of Internal Medicine, Sf. Ioan Emergency Clinical Hospital, Bucharest, Romania \\ 4) Department of Pathology, Sf. Ioan Emergency Clinical Hospital, Bucharest, Romania \\ 5) Department of General Surgery, Bagdasar-Arseni Emergency Clinical Hospital, Bucharest, Romania \\ 6) Department of Radiology, Grigore T. Popa University of Medicine and Pharmacy, Iaşi, Romania
}

\begin{abstract}
Chronic viral hepatitis $\mathrm{C}(\mathrm{CHC})$ is a global health problem, being responsible for about 399000 deaths worldwide, mostly from cirrhosis and hepatocellular carcinoma. Virus $\mathrm{C}$ infection has well known hepatic manifestations - cirrhosis and liver cancer - but the extrahepatic ones are responsible for up to $75 \%$ of morbidity in these patients. The well-known hepatitis $\mathrm{C}$ virus (HCV) lymphotropism is probably linked with the most frequent extrahepatic manifestations, mixed cryoglobulinemia and B-cell non-Hodgkin's lymphoma (BCNHL). We report a very rare entity, the case of an 82-year-old female with Child-Pugh class $A$ viral $C$ cirrhosis associated with a primary renal lymphoma (PRL). $\mathrm{PRL}$ is a non-Hodgkin's lymphoma (NHL) localized in the kidney, without any involvement of extrarenal lymphatic tissue. In addition to the case report, some relevant data from the literature were reviewed here.
\end{abstract}

Keywords: HCV, extrahepatic manifestations, PRL, treatment.

\section{Introduction}

Chronic viral hepatitis $\mathrm{C}(\mathrm{CHC})$ is a global burden, being responsible for an estimated 71 million infections worldwide (2015), 399000 deaths, mostly from cirrhosis and hepatocellular carcinoma [World Health Organization (WHO) July 2019] and for 1.75 million new infections every year [1].

Virus $\mathrm{C}$ infection has well-known hepatic manifestations - cirrhosis and liver cancer - but the extrahepatic ones should not be overlooked, these being responsible for a significant morbidity burden in the infected patients. Some studies [2] describe $\mathrm{C}$ hepatitis associated systemic manifestations (CHASMs) to be present in between $40 \%$ to $75 \%$ of $\mathrm{CHC}$ infections, more in women and in older patients. Besides its hepatotropism, hepatitis $\mathrm{C}$ virus (HCV) also has lymphotropism [3] and that could be the reason for the most frequently described extrahepatic manifestations - mixed cryoglobulinemia and B-cell non-Hodgkin's lymphoma (BCNHL).

\section{Aim}

We report a very rare entity, the case of an 82-yearold female with Child A viral $\mathrm{C}$ cirrhosis and a primary renal lymphoma (PRL). In addition to the case report, some relevant data from the literature were reviewed here.

Written informed consent was obtained from the patient's family.

\section{a Case presentation}

We report the case of an 82-year-old female known with Child-Pugh Class A viral C cirrhosis, who was admitted to our Hospital for investigations in order to start direct-acting antiviral (DAA) therapy.

She was under treatment for high blood pressure and had a history of resected facial squamous cell carcinomas (SCC) over 10 years ago.

The only abnormality detected during the physical examination of a low body mass index (BMI) patient was hepatosplenomegaly without any signs of ascites.

Laboratory tests revealed normal hemoglobin, mild thrombocytopenia $(102000 / \mathrm{mL})$, mild hepatic cytolysis [aspartate transaminase (AST) 87.9 IU/L, alanine transaminase (ALT) $66.8 \mathrm{IU} / \mathrm{L}$ ], no sign of cholestasis [total bilirubin (TB) $0.4 \mathrm{mg} / \mathrm{dL}, \gamma$-glutamyl transferase (GGT) $30 \mathrm{IU} / \mathrm{L}$ ], or hepatic failure [international normalized ratio (INR) 0.93] and a normal kidney function.

Routine chest X-ray displayed diffuse pulmonary hyperinflation and interstitial sclerofibrosis.

The abdominal ultrasound (US) revealed hepatomegaly with increased echogenicity and a homogenous structure, $14 \mathrm{~mm}$ portal vein diameter measured at the hepatic hilum and moderate splenomegaly with a homogenous structure (longitudinal splenic diameter of $185 \mathrm{~mm}$ ) and no ascites. Surprisingly, we also found a slightly hypoechoic right renal mass of $40 / 20 \mathrm{~mm}$.

This is an open-access article distributed under the terms of a Creative Commons Attribution-NonCommercial-ShareAlike 4.0 International Public License, which permits unrestricted use, adaptation, distribution and reproduction in any medium, non-commercially, provided the new creations are licensed under identical terms as the original work and the original work is properly cited. 
Since one of the mandatory criteria for DAA prescription is the exclusion of concomitant cancer, we were compelled to further extend our investigations in order to define the nature of this newly found renal mass.

The computed tomography (CT) scan described it as a right medio-renal mass of $45 / 24.3 \mathrm{~mm}$ with moderate iodophilia. Besides this, there was also described a homogenous splenomegaly $(187 / 89 \mathrm{~mm})$ without any other significant pathological findings [4] (Figure 1).

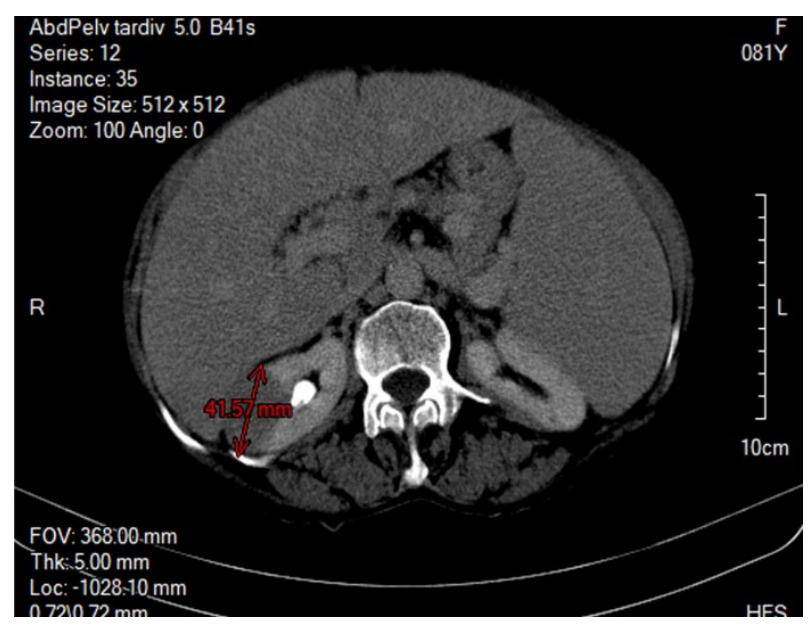

Figure 1 - CT scan right renal tumor of $42 / 25 \mathrm{~mm}$, splenomegaly of 184/89 mm. CT: Computed tomography.

The information provided by the laboratory findings and the imagistic explorations (US and CT) were evaluated by the tumor board, which included a radiologist, a gastroenterologist, a general surgeon, an urologist, an hematologist, a pathologist and an oncologist. The team's conclusion consisted in establishing the surgical indication for performing a right nephrectomy, having considered the following reasons: $(i)$ the imaging aspects of the kidney mass that suggested a Grawitz-like tumor renal cell carcinoma (RCC); (ii) the absence of the adenopathies that otherwise would have suggested a lymphoproliferative disease-associated to $\mathrm{CHC}$.

In terms of frequency, the most common kidney tumor with a similar CT appearance is RCC, non-Hodgkin's lymphoma (NHL) with primary renal localization (possibly in the context of $\mathrm{CHC}$ ) being exceptional. Consequently, the patient was referred to the Department of General Surgery where following the anesthetic-surgical evaluation and platelet administration, a laparoscopic right radical nephrectomy was performed for the suspicion of renal cancer.

The laparoscopic radical nephrectomy under general anesthesia is today the new "gold standard" surgical treatment for localized RCC because overall five-year disease-free survival rates of laparoscopic radical nephrectomy in recent series were above 90\% [5].

After being explained the risks associated with laparoscopic surgery, the risk of malignancy dissemination, injury to other organs or bleeding, as well as the potential need for conversion to open surgery if difficulties arise and the review of other surgical options, the patient opted for laparoscopy.

After obtaining the patient's consent, we have approached the lesion by laparoscopic transperitoneal access [6]. This technique provides numerous landmarks for orientation, more space and better control of the peritoneal cavity for initial surgical exploration.

In the absence of any history of abdominal surgery, we generally use the Veress needle for access into the peritoneal cavity. After the introduction of the optical and the working trocars, the surgical team proceeded to a thorough exploration of the peritoneal cavity. The absence of any other lesions confirmed during the exploration allowed the surgeon to perform the laparoscopic nephrectomy, the steps of which are briefly presented below.

After an extended section of the posterior parietal peritoneum, the right colon and the right lobe of the liver are mobilized to the median line. Then follows the wide opening of the right retroperitoneal space with detachment of the duodenum from the posterior plane. Upon discovery of the right ureter, it is ligated to prevent the descending spread of tumor cells through the urinary tract. The ureter is then used as reference for dissecting the right renal lower pole and then the renal hilum, whose arterial and venous vascular elements will be afterward isolated, ligated and then sectioned. After completing the dissection, the kidney is inserted into a plastic bag, which is extracted through an incision of about 5-6 cm length in the right iliac fossa to avoid tumor spillage into the peritoneal cavity. Hemostasis control, drainage of the right renal space and suturing of the parietal incisions are the last steps of the procedure. Intraperitoneal drainage was removed 36 hours postoperatively and the resumption of digestive tolerance and intestinal transit appeared on the second day postoperatively. The patient's discharge was on the fourth day postoperatively and the skin sutures were suppressed on the eighth day. The postoperative evolution was simple, and the laboratory findings remained within normal values.

The histopathological (HP) result revealed diffuse interstitial infiltration of renal parenchyma with small lymphoid cells, relatively pleomorphic (Figures 2-4). Our Department of Histopathology analyzed the morphological and immunoarchitectural features of the renal tumor using immunostaining techniques. The markers used and the results of this study are shown in Table 1. All of these were suggestive for a non-Hodgkin's small cell lymphoma with marginal zone (mucosa-associated lymphoid tissue - MALT) B-cell type (Figures 5-7).

Table 1 - Immunohistochemical characterization of the tumor $-P R L$

\begin{tabular}{ccc}
\hline Immunomarker & Positive & Negative \\
\hline CD3 & & $\checkmark$ \\
\hline CD5 & & $\checkmark$ \\
\hline CD10 & $\checkmark$ \\
\hline CD20 & $\checkmark$ & \\
\hline CD34 & $\checkmark$ \\
\hline CD138 & & \\
\hline BCL2 & $\checkmark$ & $\checkmark$ \\
\hline BCL6 & & $\checkmark$ \\
\hline MUM1 & & \\
\hline Ki67 & & \\
\hline
\end{tabular}

BCL: B-cell lymphoma; CD: Cluster of differentiation; MUM1: Multiple myeloma oncogene 1; PRL: Primary renal lymphoma. 


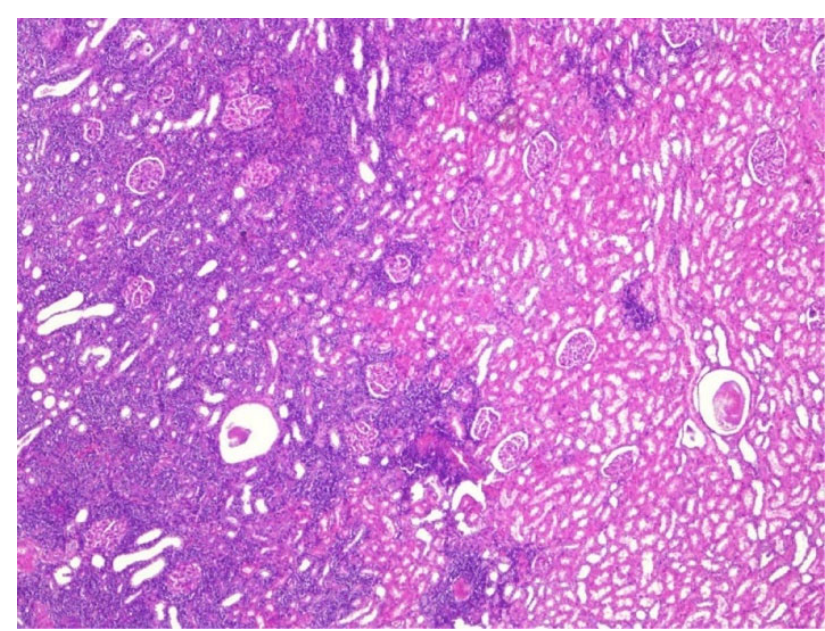

Figure 2 - Normal renal histology (right) and the interstitial infiltration of the lymphoid-like cells among the glomeruli and tubules (left). Hematoxylin-Eosin (HE) staining, $\times 40$.

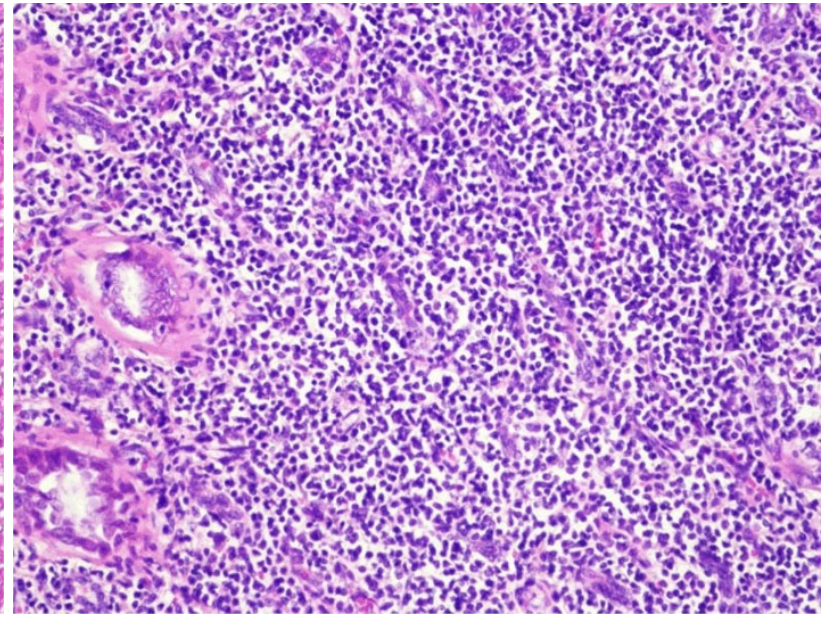

Figure $3-A$ few urinary tubules compressed by the pleomorphic lymphocytes. HE staining, $\times 200$.

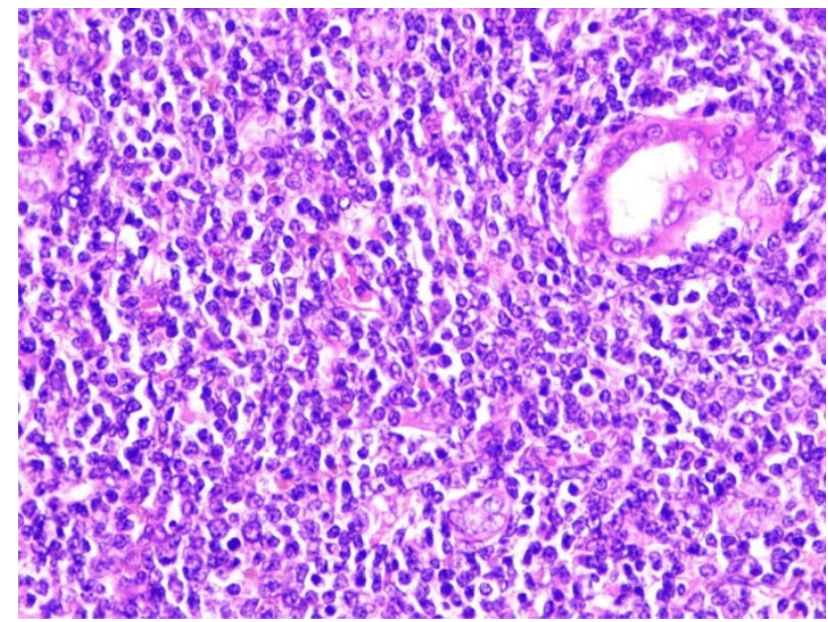

Figure 4 - The monotonous proliferation of pleomorphic round cell, lymphocyte-like, medium size, next to a urinary tubule (right). HE staining, $\times 400$.

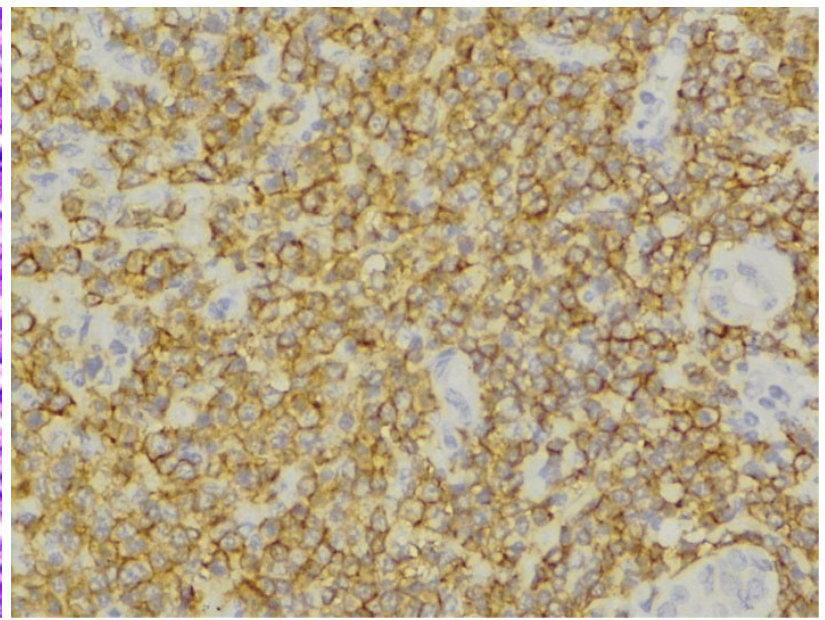

Figure 5 - Immunohistochemical (IHC) reaction for CD20 (expressed early in B-cell ontogeny; positive perimembrane intracytoplasmic), $\times 400$. CD20: Cluster of differentiation 20.

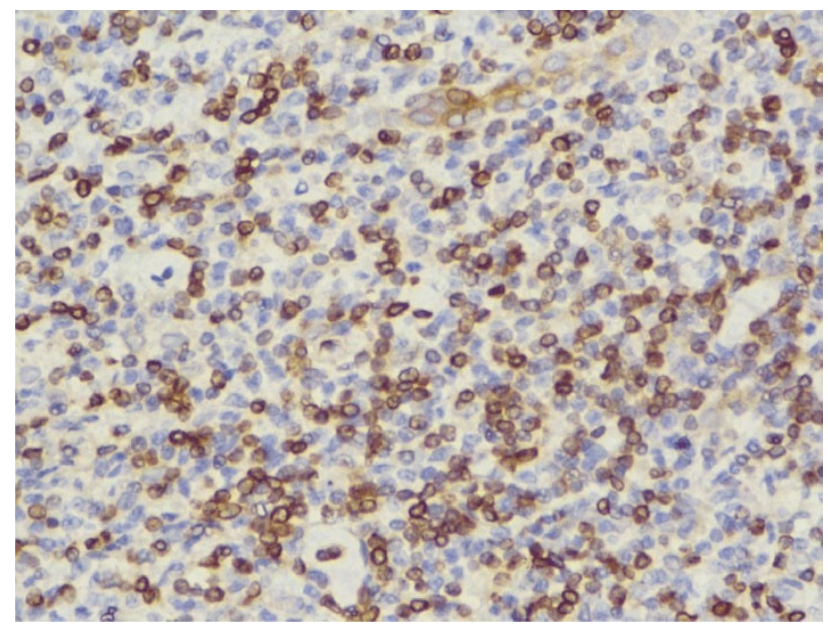

Figure 6 - IHC reaction for BCL2 (expressed by small $B$-lymphocytes of the mantle and marginal zones, intranuclear and weak intracytoplasmic positivity), $\times 400$. BCL2: B-cell lymphoma 2.

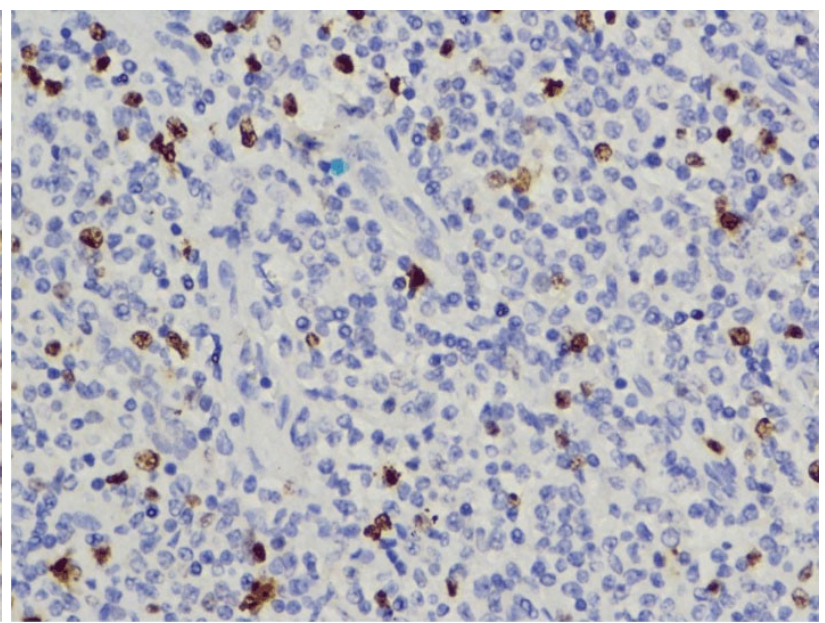

Figure 7 - IHC reaction for Ki67 (nuclear proliferative marker for cells in late G1, S, G2 and M phases), $\times 400$. 


\section{ㅁ Discussions}

Numerous extrahepatic manifestations (HCV-EHMs) have been reported along the time. Some authors consider these phenomena as being CHASMs. Whatever name they bear, in some studies up to three-quarters of the patients experienced such events of different severity, from infraclinical to incapacitating conditions $[2,7]$.

We can split these conditions into three categories: well-documented and more common, conditions with existing proofs of scientific strength of the association and others that are infrequent, whose association with HCV has yet to be proven.

The entities belonging to the second group present with higher prevalence than in control groups and are summarized as follows [8]: (i) type II diabetes, (ii) glomerulonephritis, (iii) renal insufficiency, (iv) cardiovascular disorders (stroke, ischemic heart disease), $(v)$ neurocognitive impairment, (vi) depression, (vii) sicca syndrome, (viii) auto-antibody production, (ix) dermatological disorders (porphyria cutanea tarda, lichenus planus), $(x)$ thyroid involvement, $(x i)$ malignancies, $(x i i)$ ocular manifestations, (xiii) and others being possible associated [7-10].

Even if the association of $\mathrm{CHC}$ with mixed cryoglobulinemia and BCNHL is the most frequently described, the mechanisms behind this occurrence in HCV infection is not yet completely understood. There are three theories formulated today: $(i)$ lymphocytes proliferation driven by continuous viral antigens stimulation; (ii) invasion of lymphocytes by the virus and viral replication leading to oncogenic effects; (iii) the "hit and run" theory that implies a transient invasion of lymphocytes by a virus that leads to permanent damage similar to a mutation in tumor-suppressing genes [9].

NHL was associated with HCV for the first time back in 1994 [10]. Since then, scientific interest grew and now there are described multiple histological subtypes of HCV-associated lymphomas: marginal zone lymphomas (MZLs), lymphoplasmacytic lymphoma (rare) and diffuse large B-cell lymphoma (DLBCL) - an aggressive type [9]. MZL is the most frequent type and usually has an indolent course. Currently, we know three different types of MZL: $(i)$ the extranodal type - MALT; (ii) nodal type - that implies exclusive lymph node involvement and (iii) splenic type [11].

The MALT-type NHBL is the most frequently diagnosed among HCV-infected patients [12]. Different studies reported a prevalence of $28 \% \mathrm{HCV}$ versus $2.9 \%$ in general population [13].

The top three locations according to a study [14] are the skin, salivary glands, and the orbit; less than $15 \%$ represents other sites.

PRL is a very rare entity, to date being described in medical literature worldwide less than 70 cases of PRL [15-17] and only a few associated with HCV infection upon our knowledge $[4,8]$.

Renal involvement is frequent as a dissemination site in patients with advanced stages of NHL, but PRL appears extremely rare. For a while, scientists believed that this entity does not exist due to anatomical characteristics of kidneys, which normally are lacking lymphoid tissue.
Therefore, the exact mechanism responsible for PRL formation is yet unknown. One of the theories is that it originates from the renal capsule and then infiltrates the parenchyma; another theory is that the chronic inflammatory state of the kidney is associated with infiltration with lymphoid cells that subsequently evolves to lymphoma [8].

The particularity of our case is the presence of renal lymphoma, not the usually secondary one, but the primary one in association with $\mathrm{HCV}$ infection.

In the case of chronic HCV infection, like in our patient, mechanisms underlying the occurrence of the PRL appear to be a mix of invasion of lymphocytes by the virus, lymphocytes proliferation driven by continuous viral antigens stimulation and viral replication leading to oncogenic effects (lymphotropism of the virus). Some authors consider that preexisting inflammatory processes mobilize lymphoid cells into the renal parenchyma, and while there, "the untimely oncogenic event takes place" [17].

Diagnosis of a unique nodular PRL is always difficult because usually PRL appears as kidney with multiple renal masses (60\%); less frequently as a diffuse infiltration of renal tissue $(25 \%)$, and only the least common variant is a solitary mass $(15 \%)$ [18]. Also, the solitary type is usually mistaken for RCC [4] because neither clinical manifestations, nor the US or the radiological findings are specific. The patients can present with gross hematuria, acute/chronic kidney failure, flank pain, weight loss, but can also be asymptomatic, as was our patient $[19,20]$. US, even if non-specific, is usually the first that raises suspicion. It can only describe diffuse nephromegaly or the presence of an inhomogeneous hypoechoic mass [21]. The CT scan frequently depicts a low vascularized tumor, which is an important detail in the differential diagnosis with RCC and other renal tumors that are hypervascularized. In our case, the CT scan described a mass with moderate enhancement. Magnetic resonance imaging (MRI), useful for patients with a history of contrast medium allergy or suffering of renal insufficiency, shows lesions that are typically $\mathrm{T} 1$ hypointense and T2 isointense to hypointense $[18,21,22]$. Positron emission tomography (PET)-CT is another imaging technique that is very useful in detecting small lesions therefore with an important role in the staging of the disease, exclusion of other concomitant localization, and follow-up after treatment but with the disadvantage of lower accessibility [22].

Since the clinical manifestations are so diverse and none of the imaging techniques has high enough sensitivity and specificity for the PRL for the diagnostic to be established, the "gold standard" remains microscopic histological examination. In most reported cases [23], the HP diagnosis was DLBCL, but in our case, nonHodgkin's small cell lymphoma with marginal zone (MALT) B-cell type.

Besides the presence of the renal mass, the following criteria must be met: $(i)$ exclusion of concomitant lesions affecting extrarenal visceral organs or lymph nodes at first admission, with the observation that some authors accept the presence of alongside adenopathy [24, 25], (ii) the absence of leukemic blood picture, and (iii) the absence of any sign of myelosuppression [4]. 
The publications issued before 2000 reported a poor prognosis for patients with PRL, with a median survival of less than one year. Most PRL cases published before referring to lesions that disseminated rapidly from their origin [17]. More recent studies show that responsible for the poor prognosis of PRL seem to be both the delayed diagnosis due to the indolent evolution and the histological behavior of the disease [26].

The latest large-scale analysis of the PRL survival revealed that the relative survival (RS) rates of PRL at one year, five years and 10 years were $78 \%, 64 \%$ and $55 \%$, respectively. In addition, the RS for patients diagnosed between 2000 and 2013 was better than that of patients diagnosed during the last two decades before 2000. On the other hand, the survival analysis also demonstrated an advantage for patients who were younger, females, had disease in early stages (stage I and II), received surgical treatment and had the MZL form [27]. We can conclude that the cure of renal lymphoma is possible, at least for certain forms and in early stage.

\section{Conclusions}

PRL is a very rare disease. In this study, we report a case of PRL discovered incidentally in a patient investigated for HCV. The patient was asymptomatic, and the tumor was identified during a routine US scan. One of the particularities of this case is the moderate enhancement of the tumor described on CT scan. Due to this fact, one could not exclude the diagnostic of RCC, and the patient was addressed for surgical resection. The histopathological exam described lymphoid proliferation with small lymphocytes suggestive for marginal zone (MALT) BCNHL. Because we did not find any other extrarenal lesions (visceral or lymph nodes) and no leukemic blood picture or sign of myelosuppression the final diagnostic of PRL was established. A subsequent interdisciplinary evaluation after the surgical procedure decided that the patient must follow DAA therapy for $\mathrm{HCV}$ and then follow-up and hematological treatment if it is necessary. One year later, no sign of local recurrence could be identified during follow-up.

\section{Conflict of interests}

The authors declare that they have no conflict of interests.

\section{Authors' contribution}

Mircea Liţescu and Laura Paverman contributed to the writing of the manuscript. Ion Dina and Valentin Titus Grigorean verified and approved the final form of the document.

\section{References}

[1] World Health Organization (WHO). Global hepatitis report, 2017. WHO, Geneva, 2017, 7. https://apps.who.int/iris/bit stream/handle/10665/255016/9789241565455-eng.pdf;jsess ionid=456BE6A3D0D3BEBFA9FEC07F9ED209FC?sequence $=1$

[2] Cacoub P, Poynard T, Ghillani P, Charlotte F, Olivi M, Piette JC, Opolon P. Extrahepatic manifestations of chronic hepatitis C. MULTIVIRC Group. Multidepartment Virus C. Arthritis Rheum, 1999, 42(10):2204-2212. https://doi.org/10. 1002/1529-0131(199910)42:10<2204::AID-ANR24>3.0.CO; 2-D PMID: 10524695
[3] Durand T, Di Liberto G, Colman H, Cammas A, Boni S, Marcellin $\mathrm{P}$, Cahour A, Vagner S, Féray C. Occult infection of peripheral $B$ cells by hepatitis $C$ variants which have low translational efficiency in cultured hepatocytes. Gut, 2010, 59(7):934-942. https://doi.org/10.1136/gut.2009.192088 PMID: 20442199

[4] Chen X, Hu D, Fang L, Chen Y, Che X, Tao J, Weng G, Ye X. Primary renal lymphoma: a case report and literature review. Oncol Lett, 2016, 12(5):4001-4008. https://doi.org/10.3892/ ol.2016.5173 PMID: 27895762 PMCID: PMC5104223

[5] Eskicorapci SY, Teber D, Schulze M, Ates M, Stock C, Rassweiler JJ. Laparoscopic radical nephrectomy: the new gold standard surgical treatment for localized renal cell carcinoma. ScientificWorldJournal, 2007, 7:825-836. https:// doi.org/10.1100/tsw.2007.153 PMID: 17619767 PMCID: PMC 5901220

[6] Clayman RV, Kavoussi LR, Figenshau RS, Chandhoke PS, Albala DM. Laparoscopic nephroureterectomy: initial clinical case report. J Laparoendosc Surg, 1991, 1(6):343-349. https:// doi.org/10.1089/lps.1991.1.343 PMID: 1838941

[7] Cacoub P, Comarmond C, Domont F, Savey L, Desbois AC Saadoun D. Extrahepatic manifestations of chronic hepatitis C virus infection. Ther Adv Infect Dis, 2016, 3(1):3-14. https:// doi.org/10.1177/2049936115585942 PMID: 26862398 PMCID: PMC4735500

[8] Wang XJ, Pillai AA. Extrahepatic manifestations of chronic hepatitis $C$ infection: a review and update. Curr Hepatol Rep, 2016, 15(3):150-157. https://doi.org/10.1007/s11901-016-0309-7

[9] Gill K, Ghazinian H, Manch R, Gish R. Hepatitis C virus as a systemic disease: reaching beyond the liver. Hepatol Int, 2016, 10(3):415-423. https://doi.org/10.1007/s12072-015-9 684-3 PMID: 26660706 PMCID: PMC4819925

[10] Zignego AL, Bréchot C. Extrahepatic manifestations of HCV infection: facts and controversies. J Hepatol, 1999, 31(2):369376. https://doi.org/10.1016/s0168-8278(99)80239-6 PMID: 10453955

[11] Peveling-Oberhag J, Arcaini L, Hansmann ML, Zeuzem S. Hepatitis C-associated B-cell non-Hodgkin lymphomas. Epidemiology, molecular signature and clinical management. J Hepatol, 2013, 59(1):169-177. https://doi.org/10.1016/j.jhep. 2013.03.018 PMID: 23542089

[12] de Sanjose S, Benavente Y, Vajdic CM, Engels EA, Morton LM, Bracci PM, Spinelli JJ, Zheng T, Zhang Y, Franceschi S, Talamini R, Holly EA, Grulich AE, Cerhan JR, Hartge P, Cozen W, Boffetta P, Brennan P, Maynadié M, Cocco P, Bosch R, Foretova L, Staines A, Becker N, Nieters A. Hepatitis $C$ and non-Hodgkin lymphoma among 4784 cases and 6269 controls from the International Lymphoma Epidemiology Consortium. Clin Gastroenterol Hepatol, 2008, 6(4): 451-458. https://doi.org/10.1016/j.cgh.2008.02.011 PMID: 18387498 PMCID: PMC3962672

[13] Lizardi-Cervera J, Poo JL, Romero-Mora K, Castañeda B, Pichardo-Bahena R, Morán S, Uribe $M$. Hepatitis $C$ virus infection and non-Hodgkin's lymphoma: a review and case report of nine patient. Ann Hepatol, 2006, 5(4):257-262. PMID: 17151577

[14] Arcaini L, Burcheri S, Rossi A, Paulli M, Bruno R, Passamonti F, Brusamolino E, Molteni A, Pulsoni A, Cox MC, Orsucci L, Fabbri A, Frezzato M, Voso MT, Zaja F, Montanari F, Merli M, Pascutto C, Morra E, Cortelazzo S, Lazzarino M. Prevalence of HCV infection in nongastric marginal zone B-cell lymphoma of MALT. Ann Oncol, 2007, 18(2):346-350. https://doi.org/ 10.1093/annonc/mdl388 PMID: 17071937

[15] Cyriac S, Rejiv R, Shirley S, Sagar GT. Primary renal lymphoma mimicking renal cell carcinoma. Indian J Urol, 2010, 26(3):441-443. https://doi.org/10.4103/0970-1591.70 591 PMID: 21116372 PMCID: PMC2978452

[16] Xiang H, Zhong W, Gao Q, Bai Y, Wang Z. Primary renal non-Hodgkin's lymphoma: a clinicopathologic study of six cases and review of the literature. Int J Clin Exp Pathol, 2016, 9(7):7436-7443. http://www.ijcep.com/files/ijcep0028 049.pdf

[17] Okuno SH, Hoyer JD, Ristow K, Witzig TE. Primary renal non-Hodgkin's lymphoma. An unusual extranodal site. Cancer, 1995, 75(9):2258-2261. https://doi.org/10.1002/1097-0142(19 950501)75:9<2258::aid-cncr2820750911>3.0.co;2-s PMID: 7712433 
[18] Nguyen DD, Rakita D. Renal lymphoma: MR appearance with diffusion-weighted imaging. J Comput Assist Tomogr, 2013, 37(5):840-842. https://doi.org/10.1097/RCT.0b013e3182a55 d0a PMID: 24045266

[19] Kaya A, Kanbay M, Bayrak O, Eken G, Memis L, Akcay A, Duranay M. Primary renal lymphoma associated with hepatitis C virus infection. Leuk Lymphoma, 2006, 47(9):1976-1978. https://doi.org/10.1080/10428190600681805 PMID: 17065018

[20] Hagihara M, Hua J, Iwaki Y, Inoue M, Sato T. Primary renal lymphoma: a case report and literature review. Intern Med, 2015, 54(20):2655-2659. https://doi.org/10.2169/internalmed icine.54.3368 PMID: 26466706

[21] Sheth S, Ali S, Fishman E. Imaging of renal lymphoma: patterns of disease with pathologic correlation. Radiographics, 2006 26(4):1151-1168. https://doi.org/10.1148/rg.264055125 PMID: 16844939

[22] Ganeshan D, lyer R, Devine C, Bhosale P, Paulson E. Imaging of primary and secondary renal lymphoma. AJR Am J Roentgenol, 2013, 201(5):W712-W719. https://doi.org/10.22 14/AJR.13.10669 PMID: 24147501

[23] Geetha N, Shahid A, Rajan V, Jacob PM. Primary renal lymphoma - a case report. Ecancermedicalscience, 2014, 8:
466. https://doi.org/10.3332/ecancer.2014.466 PMID: 25371707 PMCID: PMC4176444

[24] Pinggera GM, Peschel R, Buttazzoni A, Mitterberger M, Friedrich A, Pallwein L. A possible case of primary renal lymphoma: a case report. Cases J, 2009, 2:6233. https:// doi.org/10.4076/1757-1626-2-6233 PMID: 19829773 PMCID: PMC2740007

[25] Shaikh AB, Waghmare S, Koshti-Khude S, Koshy AV. Unusual presentation of non-Hodgkin's lymphoma: case report and review of literature. J Oral Maxillofac Pathol, 2016, 20(3): 510-517. https://doi.org/10.4103/0973-029X.190956 PMID: 27721619 PMCID: PMC5051302

[26] Pahwa M, Gupta N, Tyagi V, Chadha S. Primary renal lymphoma: is prognosis really that bad? Saudi J Kidney Dis Transpl, 2013, 24(4):816-817. https://doi.org/10.4103/13192442.113905 PMID: 23816741

[27] Chen J, Peng J, Zheng Y, Li S, Yang P, Wu X, Tian H, Liu H, Yang S, Wang W, Wu B. Primary renal lymphoma: a populationbased study in the United States, 1980-2013. Sci Rep, 2019, 9(1):15125. https://doi.org/10.1038/s41598-019-51635-6 PMID: 31641184 PMCID: PMC6805900

\section{Corresponding authors}

Laura Paverman, MD, PhD Student, Department of Internal Medicine, Sf. Ioan Emergency Clinical Hospital, 13 Vitan Bârzeşti Highroad, Sector 4, 042122 Bucharest, Romania; Phone +4021-334 51 90, e-mail: laura.paverman@drd.umfcd.ro Corina-Veronica Lupaşcu-Ursulescu, Associate Professor, MD, PhD, Department of Radiology, Grigore T. Popa University of Medicine and Pharmacy, 16 Universităţii Street, 700115 laşi, Romania; Phone +40-232 301603 , e-mail: corina.ursulescu@umfiasi.ro

Received: November 23, 2020

Accepted: March 19, 2021 